ORIGINAL ARTICLE

\title{
The impact of co-located NHS walk-in centres on emergency departments
}

\author{
Chris Salisbury, Sandra Hollinghurst, Alan Montgomery, Matthew Cooke, James Munro, Deborah \\ Sharp, Melanie Chalder
}

Emerg Med J 2007;24:265-269. doi: 10.1136/emj.2006.042507

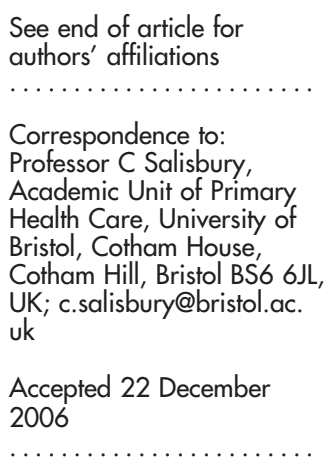

Objectives: To determine the impact of establishing walk-in centres alongside emergency departments (EDs) on attendance rates, visit duration, process, costs and outcome of care.

Methods: Eight hospitals with co-located EDs and walk-in centres were compared with eight matched EDs without walk-in centres. Site visits were conducted. Routine data about attendance numbers and use of resources were analysed. A random sample of records of patients attending before and after the opening of walk-in centres was also assessed. Patients who had not been admitted to hospital were sent a postal questionnaire.

Results: At most sites, the walk-in centres did not have a distinct identity and there were few differences in the way services were provided compared with control sites. Overall, there was no evidence of an increase in attendance at sites with walk-in centres, but considerable variability across sites was found. The proportion of patients managed within the $4 \mathrm{~h}$ National Health Service target improved at sites both with and without walkin centres. There was no evidence of any difference in reconsultation rates, costs of care or patient outcomes at sites with or without walk-in centres.

Conclusions: Most hospitals in this study implemented the walk-in centre concept to a very limited extent. Consequently, there was no evidence of any effect on attendance rates, process, costs or outcome of care.

$T$ he National Health Service (NHS) introduced the first walk-in centres during 2000, with an initial wave of 40 centres opening in various community and hospital locations. ${ }^{1}$ The aim was to improve the accessibility of NHS services by providing nurse-led information and advice for minor illnesses and injuries at times and places convenient to patients. Over the following 6 years, successive waves of walkin centres had been established, resulting in a total of 71 centres by 2005, including those opened in 2004 alongside emergency departments (EDs).

These ED walk-in centres have several aims, reflecting the current health policy. ${ }^{2}$ First, they are intended to provide people with greater choice in how they access healthcare. Rather than trying to dissuade people from attending hospital with problems that are not medical emergencies, these centres reflect a patient-centred philosophy of providing services where people choose to attend. Second, local health economies were encouraged to establish walk-in centres to relieve pressure on EDs experiencing difficulty in meeting the NHS target that patients should be seen and treated or discharged within $4 \mathrm{~h}$ of arrival. Third, these new centres were intended to offer a more appropriate environment than an ED for people attending hospital with less serious health problems.

However, there are several uncertainties about the potential effects of this strategy. Opening a walk-in centre may improve overall access, leading to increased patient throughput, without relieving pressure on the ED. Patients treated in a nurse-led walk-in centre may not have the same experience or achieve similar outcomes compared with those seen in an ED. Finally, establishing a walk-in centre may have an effect on NHS costs, including consequential costs if patients seen in a walk-in centre have a different pattern of subsequent consultations. The evaluation of the first wave of walk-in centres (few of which were co-located with EDs) suggested that, although they provided safe $^{3}$ and popular ${ }^{4}$ care, the cost of consultations

was relatively high and there was no evidence of reduced demand in neighbouring services. ${ }^{56}$

\section{METHODS}

We describe the effect of ED walk-in centres on consultation rates, waiting times, and the process, costs and outcomes of care. A survey of patients' experience is described in a companion paper. ${ }^{7}$ This is based on an evaluation of the eight walk-in centres co-located with EDs which opened during 2004.

\section{Overview of design}

A controlled before and after study was conducted. All eight sites with a new walk-in centre established in 2004 and colocated with an ED were compared with matched EDs with no co-located walk-in centre facilities. Sites with and without walk-in centres were individually matched according to three parameters: performance on the $4 \mathrm{~h}$ target, size of department (based on the number of new attendances) and the proportion of patients admitted. Using data from the third quarter of 2003/ 4, all EDs in England were ranked into quintiles. Sites were matched so that they fell into the same quintile for the $4 \mathrm{~h}$ target, and into the same or adjacent quintile for the other two parameters.

The new walk-in centres worked in a closely integrated way with their co-located EDs, so that in most instances patients were assessed and allocated to either the walk-in centre or the ED according to the nature of their problem. Therefore, it was not appropriate to compare patients seen in walk-in centres with those seen in their adjacent EDs, as there would be systematic differences between these patient groups. A more appropriate comparison was between those patients attending combined emergency/walk-in centre sites (intervention sites)

Abbreviation: ED, emergency department 


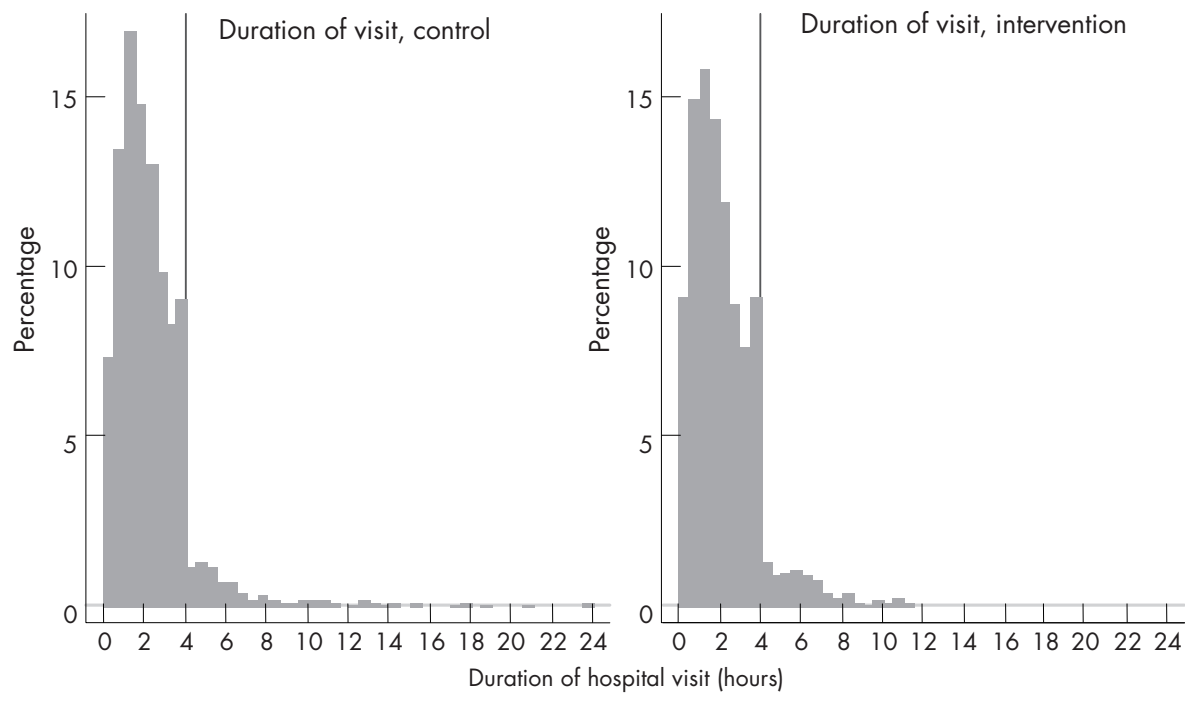

Figure 1 Duration of visits to intervention and control sites after the opening of walk-in centres. The vertical line indicates the NHS target of $4 \mathrm{~h}$ within which patients should be discharged or admitted. versus those attending similar EDs without a co-located walkin centre (control sites).

\section{Data sources}

All intervention sites were visited to collect information about the aims of the walk-in centre, staffing, policies, services provided and infrastructure. This was obtained through direct observation, interviews with managers and senior clinicians and documentary analysis. The same information was obtained from control sites via telephone interviews with local managers.

Each intervention site provided details of the number of patients consulting, admitted or discharged on a monthly basis for the period from 6 months before the opening of walk-in centre to 6 months after. Identical data were collected over the same time periods at control sites, based on the opening date at the matched site.

Each intervention site provided detailed anonymised data from patient records for 200 patients consulting before and 200 patients consulting after the opening of walk-in centre. These patients were randomly selected by the research team, using a series of computer-generated numbers matched to patient ID numbers, from those consulting in a 2 -week period at least 3 months after the walk-in centre opened, and the same period 1 year earlier, before the walk-in centre opened. The same data were collected for the corresponding time periods at control sites. Data extracted from patients' records included the facility consulted (walk-in centre and/or ED), age, sex, professional staff consulted, investigations, treatments, times of arrival, consultation, admission or discharge and type of consultation, including details of onward referrals.

From the above samples of 200 people consulting each site after opening of the walk-in centre (or during the same period at control sites), all those who were not admitted to hospital were sent an anonymous postal questionnaire 4 weeks' after their consultation. This included questions about re-consultations with the same health problem since attending the hospital, and the resolution of their problem. Further details on the survey methods are provided in the companion paper. ${ }^{7}$

An economic evaluation was conducted from the viewpoint of the NHS. Set-up costs for the walk-in centres were not included because it was not possible to identify these reliably and because it is more appropriate to compare the recurrent cost of providing services. Resource use before and after the opening of each walk-in centre was identified, measured for each site separately and valued. Sites provided data about clinical staff costs and fixed and semi-fixed costs such as administrative and clerical staff, buildings, utilities, consumables and equipment. Estimation of variable costs (investigations, treatments, medication, admissions, onward referrals and re-consultations) was based on data obtained from the anonymised patient records and the patient survey described above. Because sites with walk-in centres may make greater use of nurse practitioners, and staff costs were likely to account for most of the overall consultation cost, a "time and motion" study was conducted in four sites to obtain data about the proportion of time spent by different types of staff with different types of patients. As admissions accounted for a high proportion of the total cost per patient, but are unlikely to be related to the existence of a walk-in centre, these were excluded from the main analysis but included in a sensitivity analysis.

\section{Analysis}

Comparisons between intervention and control groups were conducted using appropriate (linear or logistic) regression models which took account of the clustered nature of the data and of individuals' different probabilities of being sampled across time and sites.

\section{RESULTS}

\section{Site visits: implementation of walk-in centres}

The latest wave of eight walk-in centres co-located with EDs had implemented the walk-in centre concept to a more limited extent than previous waves. In most sites, from the perspective of patients, the service appeared little different from the way it had been provided before. Few of the walk-in centres had a distinct visible identity and none had advertised their existence to the local population. Three of the new facilities were not known locally as walk-in centres, and in several sites the walkin centre was effectively a re-badging of a pre-existing service.

There was resistance at several sites to the concept of providing a more convenient walk-in service, due to concerns that increasing accessibility would lead to an increase in demand. Most managers and doctors believed the main function of the walk-in centre was to reduce demand on the ED rather than to increase patient choice. At the majority of sites, patients could not directly walk into the new facility, but were directed there by a receptionist or after a nurse assessment. The staffing of the walk-in centres and their colocated EDs was flexible, with nurses and doctors moving between each facility according to demand. 
Table 1 Mean visit duration and compliance with $4 \mathrm{~h}$ target

\begin{tabular}{|c|c|c|c|c|c|c|c|}
\hline & \multicolumn{2}{|l|}{ Before } & \multicolumn{4}{|l|}{ After } & \multirow[b]{2}{*}{ p Value* } \\
\hline & Intervention ED & Control ED & $\begin{array}{l}\text { Intervention } \\
\text { ED }\end{array}$ & $\begin{array}{l}\text { Intervention } \\
\text { WIC }\end{array}$ & $\begin{array}{l}\text { Intervention combined } \\
\text { ED and WIC }\end{array}$ & Control ED & \\
\hline$N$ & 1315 & 1534 & 785 & 761 & 1546 & 1530 & \\
\hline $\begin{array}{l}\text { Mean visit duration } \\
\text { (min) }\end{array}$ & 156.6 & 143.9 & 142.2 & 107.6 & 134.8 & 133.5 & 0.44 \\
\hline $\begin{array}{l}\text { Cases complying } \\
\text { with } 4 \mathrm{~h} \text { target }(\%)\end{array}$ & 87.4 & 89.0 & 94.6 & 95.6 & 94.8 & 94.8 & 0.73 \\
\hline
\end{tabular}

\section{Effect on patient throughput}

Patient throughput increased during the study, at hospitals both with and without walk-in centres. The mean increase in attendances was 813 per month $(95 \% \mathrm{CI}-30.3$ to $1655, \mathrm{p}=0.06)$ and 270 per month (95\% CI -114 to $655, \mathrm{p}=0.17$ ) in the intervention and control groups, respectively. There was no evidence of any difference in change between the intervention and control groups between the pre-and post-periods (difference in change $=542,95 \% \mathrm{CI}-347$ to $1431, \mathrm{p}=0.23$ ). Although the point estimate suggested that there was a greater increase in throughput at intervention sites (ie, those with walk-in centres), there was wide variability between individual sites. The estimate itself had a very wide CI including zero, indicating that this finding might have resulted by chance.

\section{Effect on visit duration}

The mean visit duration (time from arrival to being admitted or discharged) reduced during the study at sites with and without walk-in centres, and there was no significant difference between these types of sites. The proportion of patients managed within the target time of $4 \mathrm{~h}$ was $94.8 \%$ at both intervention and control sites. Table 1 provides details of these results. Figure 1 illustrates the effect of the $4 \mathrm{~h}$ target on waiting times.

\section{Process of care}

There were few differences between the processes of care provided at sites with and without walk-in centres, in terms of investigations and treatments. However, patients attending a walk-in centre were more likely to be managed by a nurse, without the involvement of a doctor. Of patients seen in a walkin centre, only $39.5 \%$ saw a doctor, compared with $95.7 \%$ of patients in EDs with a co-located walk-in centre and $86.6 \%$ of patients in control EDs. The value of this comparison is limited because patients were, in most cases, being allocated at intervention sites to the walk-in centre because they were suitable for nurse care.

\section{Resource utilisation and costs}

Table 2 shows the estimated total cost by the resource use group for the January-March quarter before and after the opening of the walk-in centres. The year-on-year total cost increased by $22 \%$ in the intervention group and by $10 \%$ in the control group. The differential between the two groups is largely due to the difference in the increase in clinical staff costs of $28 \%$ in the intervention group and $15 \%$ in the control group.

Table 3 shows the cost per patient. Costs increased at the intervention sites by $£ 6.22$ per patient, but costs at the control sites also increased ( $£ 8.28$ per patient), so there was no evidence of any difference between the change in cost per patient at the intervention sites compared with that at the control sites $(-£ 3.06 ; 95 \%$ CI -16.50 to 10.39). When admission costs are included in a sensitivity analysis, there remains no evidence of difference in the change in cost per patient ( $-£ 20.97 ; 95 \%$ CI -64.98 to 23.04 per patient).

\section{Patient outcome and reconsultation}

A total of 704 patients completed and returned a questionnaire successfully, giving an overall survey response rate of $36.1 \%$. Almost half of these respondents had a reconsultation about the same problem in the 4 weeks after they attended the hospital, and the majority of these consultations were with doctors or nurses in general practice (table 4). There was no evidence of any difference between patients seen at hospitals with or without walk-in centres; nor was there any evidence of differences in patient outcomes (table 5).

Table 2 Estimated total cost (£000) of intervention and control sites for a 3-month period January-March in 2004 and 2005 by category of resource use

\begin{tabular}{|c|c|c|c|c|}
\hline & \multicolumn{2}{|c|}{ Before (January-March 2004) } & \multicolumn{2}{|c|}{ After (January-March 2005) } \\
\hline & Intervention ED & Control ED & $\begin{array}{l}\text { Intervention } \\
\text { combined ED and WIC }\end{array}$ & Control ED \\
\hline Doctors & 3086 & 3323 & 4172 & 4055 \\
\hline Nurses & 4904 & 4297 & 6062 & 4740 \\
\hline Other clinical staff & 161 & 39 & 198 & 48 \\
\hline All clinical staff & 8151 & 7659 & 10432 & 8843 \\
\hline Other fixed and semi-fixed costs & 3502 & 1997 & 4452 & 2266 \\
\hline Total fixed and semi-fixed costs & 11653 & 9656 & 14884 & 11109 \\
\hline Investigations & 1656 & 2696 & 2080 & 2895 \\
\hline Medication & 280 & 157 & 213 & 164 \\
\hline Onward referral (outpatients) & 2263 & 2892 & 2209 & 2797 \\
\hline Re-consultations* & 1041 & 988 & 1229 & 1044 \\
\hline Total variable costs & 5240 & 6733 & 5731 & 6900 \\
\hline Total cost & 16893 & 16389 & 20615 & 18009 \\
\hline
\end{tabular}

$E D$, emergency department; WIC; walk-in centre.

*Including general practitioner, practice nurse, walk-in centre or NHS Direct. 
Table 3 Estimated total cost per patient $(£)$ by category of resource use

\begin{tabular}{|c|c|c|c|c|}
\hline & \multicolumn{2}{|l|}{ Before } & \multicolumn{2}{|l|}{ After } \\
\hline & Intervention ED & Control ED & $\begin{array}{l}\text { Intervention } \\
\text { combined ED } \\
\text { and WIC }\end{array}$ & Control ED \\
\hline Doctors & 20.27 & 22.99 & 23.71 & 27.40 \\
\hline Nurses & 32.21 & 29.73 & 34.46 & 32.02 \\
\hline Other clinical staff & 1.06 & 0.27 & 1.12 & 0.33 \\
\hline All clinical staff & 53.54 & 52.99 & 59.30 & 59.75 \\
\hline Other fixed and semi-fixed costs & 23.00 & 13.82 & 25.31 & 15.31 \\
\hline Total fixed and semi-fixed costs & 76.54 & 66.80 & 84.60 & 75.05 \\
\hline Investigations & 10.87 & 18.65 & 11.82 & 19.56 \\
\hline Medication & 1.84 & 1.09 & 1.21 & 1.11 \\
\hline Onward referral (outpatients) & 14.87 & 20.01 & 12.55 & 18.90 \\
\hline Re-consultations* ${ }^{*}$ & 6.84 & 6.84 & 6.98 & 7.05 \\
\hline Total variable costs & 34.42 & 46.59 & 32.58 & 46.61 \\
\hline Total cost & 110.96 & 113.39 & 117.18 & 121.67 \\
\hline
\end{tabular}

\section{CONCLUSIONS}

In most cases, the new co-located walk-in centres seem to have implemented the original walk-in centre concept to a more limited extent than the earlier centres, although there are considerable differences between individual sites. Some walk-in centres have created a slightly different organisational environment, with a greater role for nurse management of patients compared with standard EDs, but in other cases the main change seems to be in the way that episodes of care are labelled. It is therefore unsurprising that overall there are few differences between EDs with or without co-located walk-in centres in terms of patient attendance rates, waiting times, costs or outcomes.

The intervention sites seem to have nominally achieved the aim of diverting some activity from EDs to walk-in centres, but this was mainly an exercise in streaming, with no evidence of benefit or detriment to patients or to health service costs. It is difficult to determine whether these walk-in centres have achieved the aim of helping EDs meet access targets. Visit durations improved at sites both with and without walk-in centres, and it is likely that those sites without walk-in centres used other strategies to reduce waiting times. ${ }^{89}$ The current data support the findings of previous research that the waiting time target has had a galvanising effect on patient management within EDs, with many patients being admitted or discharged just within the $4 \mathrm{~h}$ limit. ${ }^{10}$

There seems to be a disconnection between the centrally determined aims of walk-in centres alongside EDs and the way in which this policy has been implemented locally. This may reflect a perceived tension between the aims of improving access to care and at the same time reducing pressures on colocated EDs. Historically, EDs have struggled to meet increasing demand, while also being expected to reduce the waiting times. They have used various strategies to discourage people from attending with conditions that are neither accidents nor emergencies. ${ }^{11}$ Encouraging people to "walk in" with any problem to suit the convenience of the individual requires a major cultural shift in attitude on the part of service providers, which has not yet been achieved.

This study has a number of limitations. First, it was conducted after the centres had been open for only a few months, and the organisational model and patients' use of the new facilities may change once the facility is well established. Second, most of the

Table 4 Re-consultations about the same problem

\begin{tabular}{|c|c|c|c|c|c|}
\hline & \multicolumn{4}{|l|}{ After } & \multirow[b]{2}{*}{ p Value* } \\
\hline & Intervention ED (\%) & Intervention WIC (\%) & $\begin{array}{l}\text { Intervention: combined ED } \\
\text { and WIC (\%) }\end{array}$ & Control ED (\%) & \\
\hline \multicolumn{6}{|c|}{ Have you been back to the hospital or consulted another healthcare professional about the same problem since your visit? } \\
\hline $\mathrm{n}$ & 115 & 215 & 330 & 362 & 0.69 \\
\hline Yes & $54(48.2)$ & 95 (43.3) & $149(46.6)$ & $177(48.5)$ & \\
\hline No & $61(51.8)$ & $120(56.7)$ & $181(53.4)$ & $185(51.5)$ & \\
\hline \multicolumn{6}{|c|}{ Who have you consulted about the same problem? } \\
\hline n & $53+$ & $93+$ & $146+$ & $172 \dagger$ & \\
\hline General Practitioner (GP) & $34(62.7)$ & $52(55.2)$ & $86(60.5)$ & $96(56.3)$ & 0.72 \\
\hline Nurse at GP surgery & $6(10)$ & $7(8.3)$ & $13(9.5)$ & $23(13.3)$ & 0.42 \\
\hline & $8(14.9)$ & $18(18.2)$ & $26(15.9)$ & $22(13.1)$ & 0.53 \\
\hline NHS WIC & $0(0)$ & $7(5.7)$ & $7(1.7)$ & $7(3.8)$ & 0.16 \\
\hline Outpatient department & $7(16.6)$ & $16(19.0)$ & $23(17.3)$ & $40(22.3)$ & 0.43 \\
\hline NHS Direct helpline & $1(.6)$ & $2(3.3)$ & $3(1.4)$ & $4(2.4)$ & 0.58 \\
\hline Other & $11(18.1)$ & $13(16.7)$ & $24(17.7)$ & $35(21.3)$ & 0.48 \\
\hline
\end{tabular}

$E D$, emergency department; WIC, walk-in centre.

*Comparison between intervention combined and control sites, using appropriate regression models, allowing for clustering and sampling probability. Percentages in the table also take account of the probability of being sampled.

†Some of those who indicated that they re-consulted did not indicate where, so the denominator is less than the total number of people answering positively to the previous question. Some people consulted in more than one place, so column totals exceed $100 \%$. Percentages in table also take account of the probability of being sampled. 
Table 5 Outcome: patient improvement

\begin{tabular}{lllll}
\hline & $\begin{array}{l}\text { Intervention ED } \mathbf{n = 1 1 4} \\
(\%)\end{array}$ & $\begin{array}{l}\text { Intervention WIC } \\
\mathbf{n}=\mathbf{2 2 1}(\%)\end{array}$ & $\begin{array}{l}\text { Intervention combined } \\
\text { ED and WIC } \mathbf{n = 3 3 5}(\%) \text { Control ED } \mathbf{n = 3 5 8}(\%) \mathbf{p} \text { Value* }\end{array}$ \\
\hline $\begin{array}{l}\text { How much has this problem improved, if at all? } \\
\text { Very much better }\end{array}$ & $45(37.5)$ & $90(43.6)$ & $135(39.5)$ & $142(39.6)$ \\
Much better & $36(31.6)$ & $91(39.0)$ & $127(34.1)$ & $138(38.2)$ \\
No change & $18(18.0)$ & $28(12.1)$ & $46(16.0)$ & $48(13.5)$ \\
Much worse & $3(3.0)$ & $3(1.0)$ & $6(2.4)$ & $8(2.4)$ \\
Very much worse & $2(1.6)$ & $3(1.3)$ & $5(1.5)$ & $9(2.6)$ \\
Not applicable & $10(8.3)$ & $6(3.0)$ & $16(6.5)$ & $13(3.7)$ \\
\hline
\end{tabular}

*Comparison between intervention combined and control sites, using appropriate regression models, allowing for clustering and sampling probability. Percentages in table also take account of probability of being sampled.

data were collected from routine records, which may be of uncertain quality. Third, the low survey response rate limits the generalisability of the findings on patients' experience reported here. Finally, although it included all the new EDs-focused walkin centres in England, the small number of sites provides limited power to detect quantitative differences.

Establishing walk-in centres co-located with EDs is just one of several wide ranging initiatives intended to provide people with choice as to how they access care. ${ }^{12}$ This study does not address the issue of other alternatives that might be adopted to improve waiting times in EDs or to improve access to primary care. The investment used to introduce walk-in centres could equally have been utilised in existing EDs, used to expand emergency nurse practitioner roles or increase integration with primary care services outside hospital. Further research should therefore compare the different models of organisation in order to determine the optimal approach.

\section{ACKNOWLEDGEMENTS}

We thank patients and staff in NHS walk-in centres and EDs who participated in the various components of the evaluation. We also thank Miss Susan Sprigge, Miss Sally Ogden, Ms Ita Connolly and Dr Jonathan Benger for their valuable help.

\section{Authors' affiliations}

Chris Salisbury, Sandra Hollinghurst, Alan Montgomery, Deborah Sharp, Melanie Chalder, Academic Unit of Primary Health Care, University of Bristol, Bristol, UK

Matthew Cooke, Warwick Medical School, University of Warwick, Warwick, UK

James Munro, Medical Care Research Unit, School of Health and Related Research, University of Sheffield, Sheffield, UK
Funding: This research has been conducted independently by the University of Bristol, funded by the Department of Health. The views expressed in this publication are those of the authors and not necessarily those of the Department of Health.

Competing interests: None.

Ethical approval was given by the Metropolitan Multicentre Research Ethics Committee, London, UK.

\section{REFERENCES}

1 NHS Executive. NHS primary care walk-in centres. Leeds: NHSE, 1999 (HSC 1999/116)).

2 Department of Health. Creating a patient-led NHS. Delivering the NHS Improvement Plan, DH Publications Orderline., 2005

3 Grant C, Nicholas R, Moore L, et al. An observational study comparing quality of care in walk-in centres with general practice and NHS Direct using standardised patients. BMJ 2002;324:1556-9.

4 Salisbury C, Manku-Scott T, Moore L, et al. Questionnaire survey of users of NHS walk-in centres: observational study. Br J Gen Pract 2002;52:554-60.

5 Chalder M, Sharp D, Moore L, et al. Impact of NHS walk-in centres on the workload of other local healthcare providers: time series analysis. BMJ 2003;326:532

6 Salisbury C, Chalder M, Manku-Scott T, et al. The national evaluation of NHS walk-in centres: Final report. Bristol: University of Bristol, 2002.

7 Chalder M, Montgomery A, Hollinghurst S, et al. Comparing care at walk-in centres and A\&E: an exploration of patient choice, preference and satisfaction. Emerg Med, 2007; this issue.

8 Cooke M, Fisher J, Dale J, et al. Reducing attendances and waits in emergency departments: a systematic review of present innovations. London: NCCSDO, 2004

9 Munro J, Mason S, Nicholl J. Effectiveness of measures to reduce emergency department waiting times: a natural experiment. Emerg Med J 2006;23:35-9.

10 Locker TE, Mason SM. Analysis of the distribution of time that patients spend in emergency departments. BMJ 2005;330:1188-9.

11 Murphy AW. 'Inappropriate' attenders at accident and emergency departments II: health service responses. Fami Pract 1998;15:33-7.

12 The NHS Plan. A plan for investment. A plan for reform. London: Department of Health, 2000. 